Case Report

\title{
Management of temporomandibular joint recurrent dislocation using Dautery's procedure: report and review
}

\author{
S. K. Bhandari ${ }^{1}$, Yuvraj Issar ${ }^{1}$, Shanender Singh Sambyal ${ }^{2}$, Andrews Navin Kumar ${ }^{2 *}$
}

\author{
${ }^{1}$ Department of Dental Surgery and Oral Health Sciences, AFMC, Pune, Maharashtra, India \\ ${ }^{2}$ Department of OMFS, Army Dental Corps, Kolkata, West Bengal, India
}

Received: 20 August 2019

Revised: 05 September 2019

Accepted: 06 September 2019

\section{*Correspondence:}

Dr. Andrews Navin Kumar,

E-mail: navin.andrews@gmail.com

Copyright: (C) the author(s), publisher and licensee Medip Academy. This is an open-access article distributed under the terms of the Creative Commons Attribution Non-Commercial License, which permits unrestricted non-commercial use, distribution, and reproduction in any medium, provided the original work is properly cited.

\begin{abstract}
Temporomandibular joint (TMJ) dislocation is an involuntary forward movement of the mandible beyond the articular eminence with the condyle remaining stuck in the anterior-most position which leaves the patient unable to close his mouth. Various surgical methods have been described in literature for the management of TMJ dislocation in patients where conservative measures are not successful and need surgical intervention. This case report highlights outcome of Dautrey's method of surgical correction in three cases of recurrent bilateral TMJ dislocation. All the patients had history of manual reduction of lock jaw in the past and none was medically compromised. TMJ tomograms open mouth confirmed anterior dislocation of condyles beyond articular eminence in all three patients. Total six Dautrey's procedures were performed. All the patients showed marked improvement in pain and TMJ function with no relapse at two years follow up. Post-operative mouth opening became normal in all the patients at one year follow up. No episode of pain, clicking, deviation or TMJ dislocation was seen in follow up period of 1, 3, 6, 12, 24 months. Hence, Dautery's procedure serves as an effective management option for recurrent temporomandibular joint dislocation.
\end{abstract}

Keywords: Temporomandibular joint, Dislocation, Dautrey’s procedure

\section{INTRODUCTION}

Recurrent dislocation of the mandible is a rare but distressing condition. It is displacement of the condyle in front of the articular eminence where it is held by spasm of the muscles of mastication whereas chronic or recurrent sub-luxation which is a partial or incomplete dislocation which is self-reducing. Many reasons have been proposed for this condition, and treatments range from relatively conservative methods to various surgical interventions. The common reasons for dislocation can be iatrogenic, spontaneous, systemic disease-related, pharmacologic, trauma-related or anatomic. Whatever the underlying cause, with each successive dislocation, further episodes tend to happen more quickly. ${ }^{1}$
Dislocation of the temporomandibular joint (TMJ) represents $3 \%$ of all reported dislocated joints in the body. $^{2}$ As with other temporomandibular disorders, the highest incidence of recurrent dislocation is reported among female subjects, although the reasons for this are not well understood. ${ }^{3}$ Patients with this condition generally present with a gnawing pain in the TMJ region, opening click with a deviation of the mandible while opening wide, difficulty in closing the mouth with a closing click, depression of the skin, excessive salivation, tense and spasmodic muscles of mastication.

The surgical methods which have been used in literature either facilitate the unhindered forward and backward movement of condyle around articular eminence or 
obstruct the condylar movement ahead of the articular eminence. Eminectomy, as described by Myrhaug in 1951 , results in a decreased height of articular eminence which leads to an auto repositioning of the condyle in glenoid fossa if a dislocation occurs. ${ }^{4}$ In this procedure, the joint becomes self-reducing but disturbs the regular physiologic movement pattern of the condyle in the joint.

Obstruction to the condylar movement is described in the literature by bone grafting, mechanical obstruction using implants and a more popular procedure amongst surgeons known as Dautery's procedure. ${ }^{5-7}$ In 1933, Mayer described segmental dislocation of the zygomatic arch to act as a physiologic obstruction to condylar hypermobility. ${ }^{8}$ Ten years later, LeClerc and Girard described a similar procedure, wherein a vertical osteotomy was created in the zygomatic arch, inserting the osteotomized segment to impede the path of the hypermobile condyle. ${ }^{8}$ Modifying the paradigm yet again, in 1967 Gosserez and Dautrey described a similar procedure, similarly aimed at greenstick fracture of the zygomatic arch. ${ }^{9}$ Despite the variations, all of the procedures share a similar endpoint. Here we present our three cases which were managed effectively using Dautery's procedure with no post-operative recurrence/ complication.

\section{CASE REPORT}

Three cases (one male and two females with mean age 23.3 years) of bilateral recurrent TMJ dislocation are described who presented to us with pain, clicking and jaw deviation on full mouth opening in both joints (Figure 1). All the patients had a history of manual reduction of lockjaw in the past. The clinical history about dietary habits involving wide mouth opening, betel nut chewing, and trauma did not contribute to the aetiology of hypermobility in any of the cases. All patients had been treated non-surgically at various centres of our organization for at least 01 year using analgesics, sedatives and anti-inflammatory medication with or without splints. None of the patients was medically compromised, had no neurological/psychogenic disorders and were not under any anti-psychotic medications. Preoperative mouth opening in the only male patient was 60 $\mathrm{mm}$, and in the remaining two female patients were 56 $\mathrm{mm}$ and $54 \mathrm{~mm}$. All patients had no missing teeth. TMJ tomograms open mouth confirmed an anterior dislocation of condyles beyond articular eminence in all patients. A total of six Dautery's procedures were performed. We did not use miniplate fixation in any of the patients. All patients were followed up for two years with recalls after 01, 03, 06, 12 and 24 months. Any recurrence of TMJ pain and general well-being of all the patients was noted and mouth opening was recorded at each appointment.

Dautery's procedure was performed under general anesthesia using preauricular approach with temporal extension in all the patients (Figure 2A and B). After reaching temporal fascia the flap was undermined anteriorly. An oblique incision at $45^{\circ}$ was made into the temporalis fascia over the root of the zygomatic arch and the arch was exposed by subperiosteal dissection. Care was taken to expose articular eminence fully with no breach in TMJ capsule and minimal zygomatic arch stripping. Articular eminence was confirmed by palpating condylar movements behind it on opening and closing the patient's mouth. Using an osteotome, an oblique osteotomy was performed of the zygomatic arch in the cranial posterior to the caudal anterior direction anterior to articular eminence. The arch was sprung first laterally very slowly and then downwards by controlled pressure with a nasal septal osteotome to prevent its complete fracture. With its inherent elastic property, the arch was stabilized in a sagittal groove made below articular eminence. No miniplate fixation was required in any of the cases. MMF was not required, and patients were instructed not to do excessive mouth opening till three weeks post-operatively. Post-operative radiograph was taken (Figure 3).

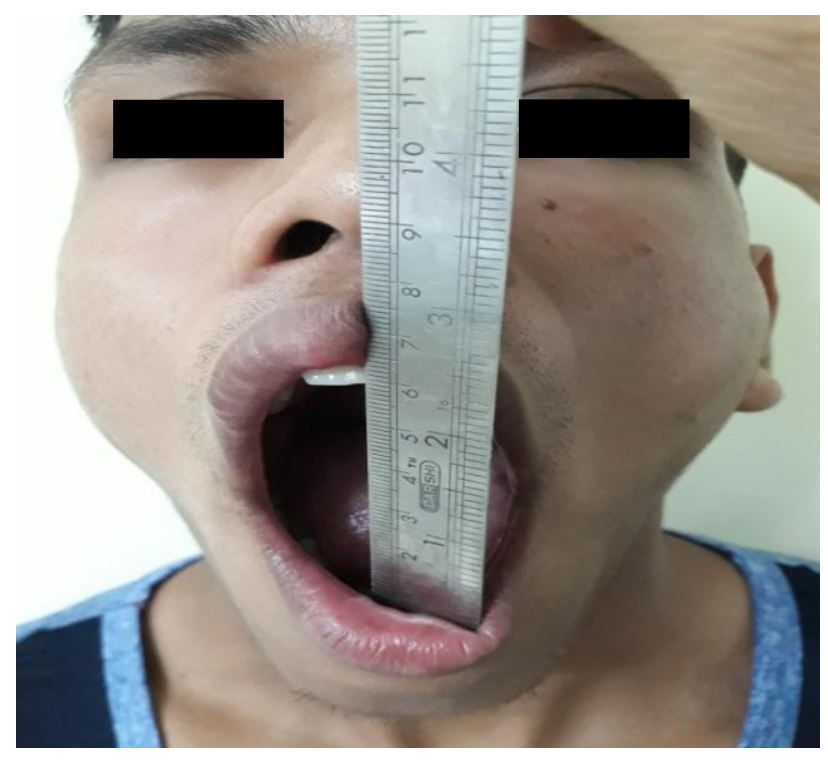

Figure 1: Bilateral TMJ dislocation and jaw deviation on full mouth opening.
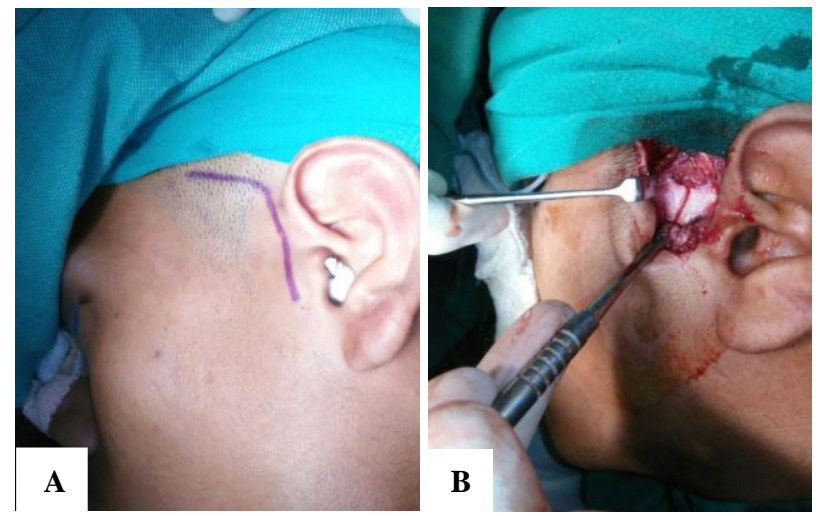

Figure 2: (A) Surface marking for preauricular approach with temporal extension; (B) preauricular approach with temporal extension (intra-operative). 


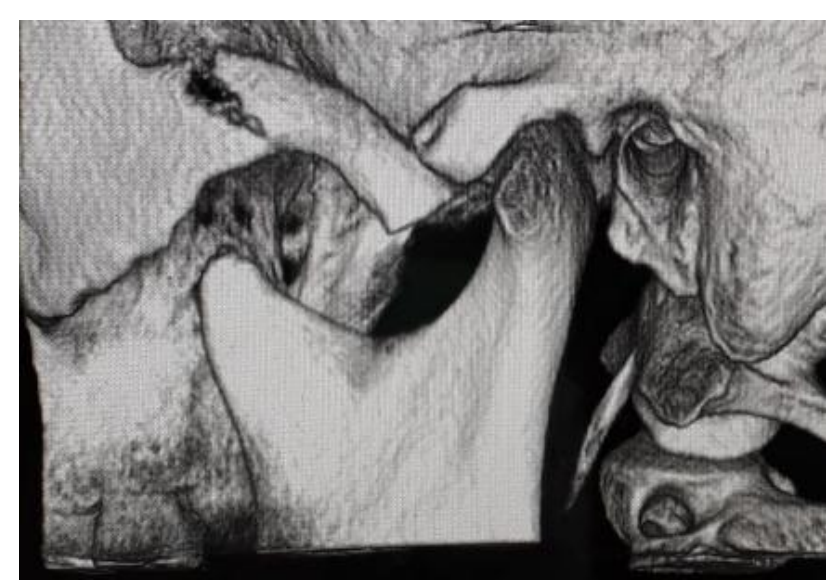

Figure 3: Post-operative radiograph.
The mean pre-operative maximum mouth opening (MIO) was $56.33(\mathrm{SD} \pm 2.52)$. Mean post-operative $\mathrm{MIO}$ at interval of 01 month, 03 month, 06 month 12 month and 24 months were $32.33 \mathrm{~mm}(\mathrm{SD} \pm 2.52), 35.00 \mathrm{~mm}$ (SD \pm $3.00), 39.00 \mathrm{~mm}(\mathrm{SD} \pm 3.6), 41.67 \mathrm{~mm}(\mathrm{SD} \pm 2.8)$ and $41.67 \mathrm{~mm}$ (SD \pm 2.99 ) respectively (Table 1). The postoperative healing period was uneventful and immediate reduction in mouth opening was noticed in all patients (Figure 4).

The preoperative mean pain score was 6.67 , with maximum 08 by patient number 2 and minimum 5 by patient number 03. In the postoperative period, the gradual reduction of pain score noted in all three patients with man value of 4.00 at 01 month, 1.33 at 03 months and 0.00 after that (Table 2 ).

Table 1: Mean maximum mouth opening.

\begin{tabular}{|c|c|c|c|c|c|c|c|c|}
\hline \multicolumn{9}{|c|}{ Descriptive statistics } \\
\hline & \multirow[b]{2}{*}{$\mathbf{N}$} & \multirow{2}{*}{ Mean } & \multirow{2}{*}{ Std deviation } & \multirow{2}{*}{ Minimum } & \multirow{2}{*}{ Maximum } & \multicolumn{3}{|c|}{ Percentiles } \\
\hline & & & & & & $25^{\text {th }}$ & $50^{\text {th }}$ (median) & $75^{\text {th }}$ \\
\hline Pre op & 3 & 56.33 & 2.517 & 54 & 59 & 54.00 & 56.00 & 59.00 \\
\hline 01 month & 3 & 32.33 & 2.517 & 30 & 35 & 30.00 & 32.00 & 35.00 \\
\hline 03 month & 3 & 35.00 & 3.000 & 32 & 38 & 32.00 & 35.00 & 38.00 \\
\hline 06 month & 3 & 39.00 & 3.606 & 35 & 42 & 35.00 & 40.00 & 42.00 \\
\hline 12 month & 3 & 41.67 & 2.887 & 40 & 45 & 40.00 & 40.00 & 45.00 \\
\hline 24 month & 3 & 41.67 & 2.887 & 40 & 45 & 40.00 & 40.00 & 45.00 \\
\hline
\end{tabular}

Table 2: Mean pain score.

\begin{tabular}{|c|c|c|c|c|c|c|c|c|}
\hline \multicolumn{9}{|c|}{ Descriptive statistics } \\
\hline & \multirow{2}{*}{$\mathbf{N}$} & \multirow{2}{*}{ Mean } & \multirow{2}{*}{ Std deviation } & \multirow{2}{*}{ Minimum } & \multirow{2}{*}{ Maximum } & \multicolumn{3}{|c|}{ Percentiles } \\
\hline & & & & & & $25^{\text {th }}$ & $50^{\text {th }}$ (median) & $75^{\text {th }}$ \\
\hline Pre op & 3 & 6.67 & 1.528 & 5 & 8 & 5.00 & 7.00 & 8.00 \\
\hline 01 month & 3 & 4.00 & 1.000 & 3 & 5 & 3.00 & 4.00 & 5.00 \\
\hline 03 month & 3 & 1.33 & 1.155 & 0 & 2 & 0.00 & 2.00 & 2.00 \\
\hline 06 month & 3 & 0.00 & 0.000 & 0 & 0 & 0.00 & 0.00 & 0.00 \\
\hline 12 month & 3 & 0.00 & 0.000 & 0 & 0 & 0.00 & 0.00 & 0.00 \\
\hline 24 month & 3 & 0.00 & 0.000 & 0 & 0 & 0.00 & 0.00 & 0.00 \\
\hline
\end{tabular}

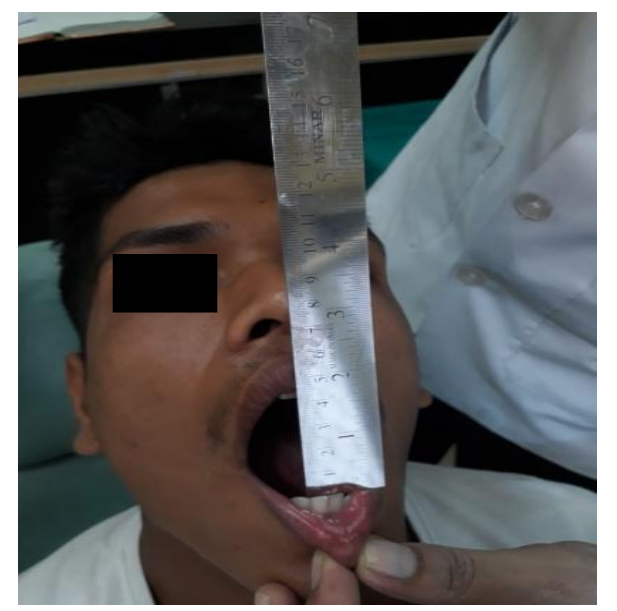

Figure 4: Post-operative reduction in mouth opening.
No patient developed any facial nerve deficit. No episode of pain, clicking, deviation or TMJ dislocation was seen in follow up period of 01, 03, 06, 12, 24 months.

\section{DISCUSSION}

Chronic recurrent dislocation is caused by dysfunction of the components of the TMJ, including abnormal articular eminence, glenoid fossa, or condylar head; relaxation of the ligaments and the capsule; or dysfunction of the muscles of mastication. Chronic recurrent dislocation is characterized by a condyle that slides over the articular eminence, catches briefly beyond the eminence and then returns to the fossa.

The various causes can be iatrogenic, spontaneous, trauma-related, systemic diseases related, pharmacologic 
or anatomic. Iatrogenic causes can be intubation/laryngoscopy, dental or ear, nose and throat procedures, gastrointestinal endoscopies. Spontaneous causes are laughter, yawning, vomiting, or singing. Trauma-related is where injury impact comes on TMJ. Systemic diseases like Ehlers-Danlos/connective tissue disease, neurodegenerative/neurodysfunctional diseases, i.e., Huntington disease, epilepsy, Parkinson disease, multiple sclerosis, muscle dystrophies/dystonias, are related to chronic TMJ dislocation. Other pharmacologic causes like phenothiazines, metoclopramide and anatomic causes like steep eminence, abnormal condylar shape and atypical disc position have also been cited. ${ }^{12}$

A brief review of the literature indicates the many and varied techniques employed over the years to treat this condition. Prolonged immobilisation of the temporomandibular joint using intermaxillary fixation has been used for recurrent dislocation of the mandible but does nothing to eliminate the cause. Schultz described the injection of a sclerosing solution into the joint to produce capsular fibrosis and eliminate excessive condylar movement. This technique is successful in cases of hypermobility, but its efficacy in patients with severe recurrent dislocation is doubtful. Thoma advocated a bone graft onlay to the articular eminence. Many surgeons favour this approach despite involving a separate donor site. Dingman recommended meniscectomy to treat this condition. However, this involves interfering with the joint space. To avoid this, capsular surgery is favoured by many operators. Plication of the capsule, which is an operation for reducing the size of a hollow viscus, was first described by Hudson. Myrhaug, Irby, and Hale describe the reduction in the height of the articular eminence so that the condyle will readily slip back into the fossa if subluxation occurs.

In 1975, Dautrey described the principle of the operation in which the zygomatic arch is cut and sprung downwards, which restricts excessive forward movement of the condyle. The advantage of this method is that it is less invasive, involving a short incision in the hairy temporal region, a small operative field, local anaesthetic and short operating time. There is no need for postoperative intermaxillary fixation or bone transplantation. $^{13}$

Lawlor stated that it was desirable to carry out this procedure in patients under 32 years of age, as inherent elasticity of the bone is reduced. ${ }^{14}$ However, Iizuka et al reported excellent results in 12 patients aged from 17 to 59 years old (mean 28). ${ }^{15}$ Srivastava et al reported successful treatment of 11 of 12 patients over 25 years old (mean 36). ${ }^{16}$ In our study, 12 patients whose ages ranged from 38 to 94 years old (mean 72) had successful results. Kobayashi et al used Dautery's procedure in elderly patients, giving a limited exposure around the articular eminence and careful attention to springing down the arch. ${ }^{17}$
Gadre et al treated 20 patients (12 males and 8 females, mean age 37.55 years) with bilateral chronic recurrent dislocation successfully with a total resolution of the recurrent dislocation immediately. ${ }^{18}$ Sahoo and Bhardwaj evaluated the increase in height and change in position of neo-articular tubercle in cases treated by Dautrey's procedure. In radiological evaluation using orthopantomogram (OPG), an average increase in articular tubercle height was $3.65 \mathrm{~mm}$ on the right side, and $3.52 \mathrm{~mm}$ on left side. The mean anterior shift of articular tubercle lowest point was $4.56 \mathrm{~mm}$ on the right side and $4.51 \mathrm{~mm}$ on the left side which was statically highly significant. ${ }^{19}$

Jeyaraj operated twenty-five were by the Dautrey's procedure, 25 by articular eminectomy alone and the remaining 25 by eminectomy followed by meniscal plication and tethering. Dautrey's procedure yielded more gratifying and stable results, leading to successful and permanent correction of chronic recurrent dislocation of the TMJs. ${ }^{20}$

Among the advantages offered by the Dautrey procedure is that it does not interfere with the normal working of the temporomandibular joint yet prevents abnormal excursions of the condyle. It increases the height of the articular eminence and provides a bony obstruction to excessive forward movement without the need for a bone graft from another site. There is no interference with the joint cavity or with the capsule of the joint. Finally, it is a technique which avoids the introduction of foreign material into the joint area.

\section{CONCLUSION}

Dautery's procedure serves as an effective management option for recurrent temporomandibular joint dislocation.

\section{Funding: No funding sources \\ Conflict of interest: None declared \\ Ethical approval: Not required}

\section{REFERENCES}

1. Kai S, Kai H, Wakayama E, Tobata $\mathrm{O}$ et al. Clinical symptoms of open lock position of the condyle. Relation to anterior dislocation of the temporomandibular joint. Oral Surg Oral Med Oral Path. 1992;74:143-8.

2. Hale RH. Treatment of recurrent dislocation of the mandible. Review of literature and report of cases. J Oral Surg. 1972;30:527-30.

3. Lovely FW, Copeland RA. Reduction eminoplasty for chronic recurrent luxation of the temporomandibular joint. J Can Dent Assoc. 1981;3:179-84.

4. Myrhaug H. A new method of operation for habitual dislocation of the mandible. Acta Odontol Scand. 1951;9:247. 
5. Medraa AM, Mahrous AM. Glenotemporal osteotomy and bone grafting in the management of chronic recurrent dislocation and hypermobility of the temporomandibular joint. Br J Oral Maxillofac Surg. 2008;46:119-22.

6. Buckley MJ, Terry BC. Use of bone plates to manage chronic mandibular dislocation: report of cases. J Oral Maxillofac Surg. 1988;46:998-1002.

7. Howe AG, Kent JN, Farrell CD, Poldmore SJ. Implant of articular eminence for recurrent dislocation of the temporomandibular joint. J Oral Surg. 1978;36:523-6.

8. Mayer L. Recurrent dislocation of the Jaw. J Bone Surg. 1933;15:889-96.

9. Undt G, Kermer C, Piehslinger E, Rasse M. Treatment of recurrent mandibular dislocation, Part 1; LeClercblocking procedure. Int J Oral Maxillofac Surg. 1997;26:92-7.

10. Gosserez M, Dautrey J. Osteoplastic bearing for treatment of temporomandibular luxation. Transaction of Second Congress of the International Association of Oral Surgeons, Copenhagen, Munksgaard. Int J Oral Surg. 1967;4:261.

11. Sahoo NK, Kumar P. Efficacy of Dautrey's procedure in chronic recurrent TMJ dislocation. Indian J Dent. 2013;4:52-5.

12. Liddell A, Perez DE. Temporomandibular Joint Dislocation. Oral Maxillofac Surg Clin North Am. 2015;27(1):125-36.

13. Dautrey J. Reflexions sur la chirurgie de l'articulation temporomandibulaire. Acta Stomatol Belg. 1975;72:577-81.
14. Lawler MG. Recurrent dislocation of the mandible: treatment of ten cases by the Dautrey procedure. $\mathrm{Br}$ J Oral Surg. 1982;20:14.

15. Iizuka T, Hidaka Y, Murakami K, Nishida M. Chronic recurrent anterior luxation of the mandible. Int J Oral Maxillofac Surg. 1988;17:170-2.

16. Srivastava D, Rajadnya M, Chaudhary K, Srivastava L. The Dautrey procedure in recurrent dislocation: a review of 12 cases. Int J Oral Maxillofac Surg. 1993;23:229-31.

17. Kobayashi H, Uamazaki T, Okudera H. Correction of recurrent dislocation of the mandible in elderly patients by the Dautrey procedure. $\mathrm{Br} \mathrm{J}$ Oral Maxillofac Surg. 2000;38:54.

18. Gadre KD, Kaul D, Ramanojam S, et al. Dautrey's procedure in the treatment of recurrent dislocation of the mandible. J Oral Maxillofac Surg. 2010;68:2021-4.

19. Sahoo NK, Bhardwaj PK. Radiographic assessment of changes in articular tubercle after Dautrey's procedure. J Oral Maxillofac Surg. 2013;71(2):24954.

20. Jeyaraj P. Chronic Recurrent Temporomandibular Joint Dislocation: A Comparison of Various Surgical Treatment Options, and Demonstration of the Versatility and Efficacy of the Dautrey's Procedure. J Maxillofac Oral Surg. 2018;17(1):95106.

Cite this article as: Bhandari SK, Issar Y, Sambyal SS, Kumar AN. Management of temporomandibular joint recurrent dislocation using Dautery's procedure: report and review. Int J Otorhinolaryngol Head Neck Surg 2019;5:1748-52. 